\title{
A Distributed Model Predictive Control approach for the integration of flexible loads, storage and renewables
}

\section{Ferrarini, Luca; Mantovani, Giancarlo; Costanzo, Giuseppe Tommaso}

Published in:

IEEE International Symposium on Industrial Electronics

Link to article, DOI:

10.1109/ISIE.2014.6864871

Publication date:

2014

Document Version

Early version, also known as pre-print

Link back to DTU Orbit

Citation (APA):

Ferrarini, L., Mantovani, G., \& Costanzo, G. T. (2014). A Distributed Model Predictive Control approach for the integration of flexible loads, storage and renewables. In IEEE International Symposium on Industrial Electronics (pp. 1700-1705). IEEE. https://doi.org/10.1109/ISIE.2014.6864871

\section{General rights}

Copyright and moral rights for the publications made accessible in the public portal are retained by the authors and/or other copyright owners and it is a condition of accessing publications that users recognise and abide by the legal requirements associated with these rights.

- Users may download and print one copy of any publication from the public portal for the purpose of private study or research.

- You may not further distribute the material or use it for any profit-making activity or commercial gain

- You may freely distribute the URL identifying the publication in the public portal 


\section{A Distributed Model Predictive Control approach for the integration of flexible loads, storage and renewables}

\author{
Luca Ferrarini and Giancarlo Mantovani \\ Dip. Di Elettronica, Informazione e Bioingegneria \\ Politecnico di Milano \\ 20133 Milano (Italy) \\ luca.ferrarini@polimi.it
}

\author{
Giuseppe Tommaso Costanzo \\ Center for Electric Energy and Power \\ DTU Elektro, Technical University of Denmark \\ 4000 Roskilde, Denmark \\ guco@elektro.dtu.dk
}

\begin{abstract}
This paper presents an innovative solution based on distributed model predictive controllers to integrate the control and management of energy consumption, energy storage, $P V$ and wind generation at customer side. The overall goal is to enable an advanced prosumer to auto-produce part of the energy he needs with renewable sources and, at the same time, to optimally exploit the thermal and electrical storages, to trade off its comfort requirements with different pricing schemes (including real-time pricing), and apply optimal control techniques rather than sub-optimal heuristics.
\end{abstract}

Keywords-Smart Grids, Model Predictive Control, Smart Buildings, Renewable Energy Integration.

\section{ABBREVIATIONS}

GHG - Green House Gas

HVAC - Heat, Ventilation and Air Conditioning

MPC - Model Predictive Control

PCC - Point of Common Coupling

PV - Photo Voltaic

RES - Renewable Energy Resource

SOC - State of Charge

\section{INTRODUCTION}

Since decades, the energy-related issues, from GHG effects to carbon footprint, to reduction of fossil sources is an everyday topic of discussion in many public and private sectors. Extensive research has proven that there is no a clear and single solution to the problem of feeding energy to the world in a sustainable way. On the contrary, this goal can be pursued with a suitable combination of techniques and technologies. In particular, an attractive approach consists in making the loads more flexible (to follow better the production or to deal with transmission problems), expand the usage of renewables (to ensure sustainability without side effects), and exploit energy storage to balance variability of renewable sources production.

One of the most relevant consumption of energy is due to the building sector, including the residential and commercial ones, which accounts for about $40 \%$ of total energy consumed in the industrialized world: US, Europe and China cover approximately $60 \%$ of the word total building consumption (see the DOE report [3]). In 2010 the buildings sector in USA accounted for about $41 \%$ of primary energy consumption, $44 \%$ more than the transportation sector and $36 \%$ more than the industrial sector. Similar results hold for Europe, where more than $75 \%$ of building energy is used for comfort control - that is for heating, ventilation and air conditioning.

Clearly, reaching a cost containment and energy efficiency in the building sector is as important as implementing sustainable savings. Thus, a robust control system able to provide the maximum comfort with the minimal primary energy cost is mandatory. The same control scheme is also to be used to introduce flexibility in the service to the load.

On the production side, renewables are intermittent sources not easily predictable. In this sense, prediction techniques should be reinforced, as well as the integration with energy storage systems, so that renewables can be made more programmable. Also, robust control schemes against uncertainties in the production prediction should be implemented.

This paper presents the above integration problems of flexible load, renewables and storage with the Model Predictive Control technique. The MPC is an advanced modelbased control technique which, by solving an optimization problem, provides the sequence of optimal control variables over a finite time horizon [4]. Hard and soft constraints are used to represent the system dynamics and system and comfort requirements. Additionally, to enforce robustness, the Kalman filter extension is here considered to smooth the impact of non modelled dynamics and disturbances (e.g. weather and/or energy price prediction errors).

MPC has been applied to energy efficiency under different perspectives: in [5] building thermal management via centralized economic MPC is described and applied in a setup with thermal storage (building space heating), solar and wind generation. In this study the control objective is to balance the reduction of operating costs with the maximization of users' comfort. In [6] the residential building space heating is first 


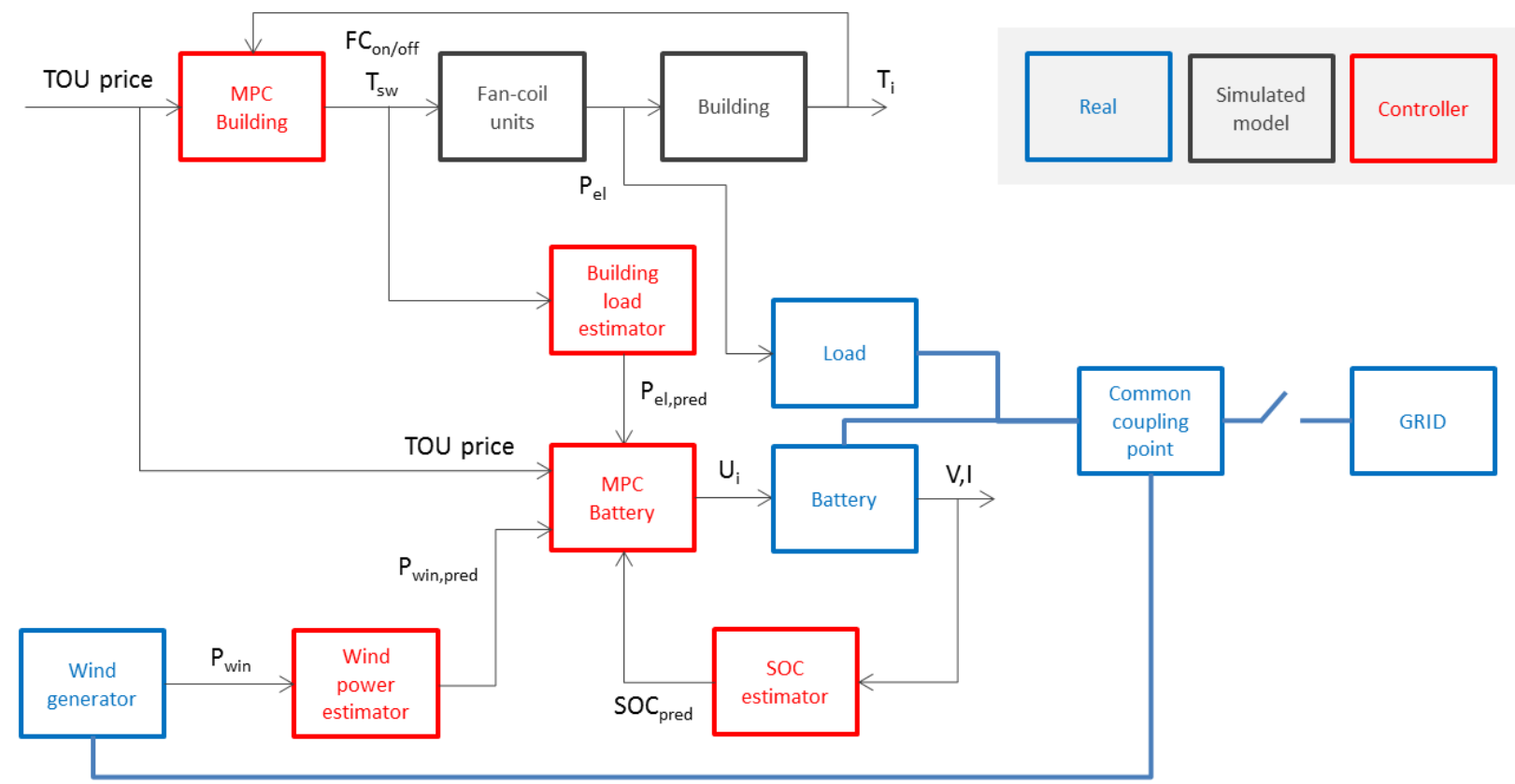

Figure 1 - Distributed control system architecture. In evidence, real components, simulated components and control blocks.

analyzed and then controlled via economic MPC, where building thermal inertia is used to shift the consumption through dynamic energy pricing. In the case study presented in [6], the heating system consists of a heat pump, whose intrinsic thermal inertia is also accounted for in the optimization and used to smooth the load factor via dynamic pricing scheme. MPC for energy efficiency of commercial building cooling systems has been investigated in [7], where thermal inertia is enhanced by a water storage connected to the chillers. Also in this study the control objective is to minimize the energy expenses while satisfying the required cooling load.

[5], [6] and [7] present similar application of deterministic MPC to the problem of enhancing energy efficiency in buildings, whereas in [8] a stochastic optimization-based approach is introduced in order to improve control performances with respect to weather prediction errors. However those architectures are based on centralized computation and model integration. The approach presented in this paper is based on distributed control architecture, which allows to have independent MPCs at devices' side that communicate via simple and asynchronous message passing. This feature eases system integration, allowing disregarding the devices low level operation and modeling, and abstracting the behavior through the MPC layer. In addition to that, the distributed approach allows defining a standard interface for information exchange between controllers. For instance, this solution brings advantages with respect to a centralized solution, such as: easy integration of controllers from different manufacturers and designed for different devices with minimum effort, enhancement of system reliability and reduction of risks related to centralized solutions, where the controller represents a single point of failure.

The paper is organized as follows: Sect. II presents the case study and discusses the advantages of the proposed distributed control solution. The architecture implementing the innovative control scheme is described in Sect. III. Sect. IV introduced the MPC for the building thermal management, while Section V describes the MPC for the integration of renewables, consumption and storage in the microgrid with the main network via point of common coupling. Simulation results are described and commented on in Sect. VI, while the conclusions and a proposal for future investigation are outlined in Sect. VII.

\section{PROJECT SCOPE}

Terms like smart consumers, smart grid and microgrid refer to a large variety of consumers, often equipped with renewables production, pursuing specific needs and targets, often very different among each other. Consequently, appropriate control strategies should be designed in order to address the consumer different needs. For example if we consider a set of buildings equipped with photovoltaic PV panels and a storage battery (with a single owner each) and a microgrid with many buildings and a single medium voltage electrical cabin, equipped with a storage battery and PV production (where building and cabin have different owners) the control goals (economic / comfort / operative) are evidently diverse. In the former case, a reasonable target can be to use the battery as a buffer for exceeding renewables production or for purchasing energy at the most convenient price for serving the building consumption. The latter's aim can instead be more related to infrastructure operation, namely minimizing the power flow at the Point of Common Coupling (i.e. the connection of the microgrid with the main grid) in order to result more stable with respect to the grid, to have smaller cables, simpler and thus cheaper equipment (transformers / converters) and a lower electrical power capacity.

The added value brought in this work goes towards the electrical and conceptual diversity outlined through the previous example. An innovative distributed control architecture for managing the equipment of the smart consumer / smart grid / microgrid is presented and parameterized with 
respect of changing objectives and system dimension. The optimization-based approach of MPC controller and the distributed architecture are suitable for this scope. In particular, we target the following scenario as test case:

- A commercial building equipped with controlled HVAC plant and a PCC power flow manager which uses a storage battery and RES (wind / PV) for serving the building while trying to minimize the power flow at PCC. The building and PCC manager belong to different stakeholders.

Although similar case studies can be elaborated and adapted, this was chosen as it can be easily scaled in the case where more buildings, batteries and heterogeneous RES are in place. Advantages given by the system as described are:

- Possibility to adapt to different electrical layouts and overall goals, with the same control architecture simply re-parameterized;

- Reduced payback times as self-consumption can be optimized;

- Stability with respect to electrical network, as PCC power flow can be limited. For the same reason it is possible to have undersized equipment and connection to the main grid;

- The distributed fashion is envisaged such as the MPC controllers need to exchange only information related to the power consumption / production of the components they control. This allows to integrate components that can be potentially produced by different manufacturers.

\section{DESCRIPTION OF THE ARCHITECTURE}

The control architecture capable of addressing the explained issues is displayed in Figure 1. The schematic depicts two main MPC controllers: a MPC for managing the building and a MPC for managing the battery. Parameters choice, control system targets and following description refers to the test scenario portrayed in Sect. II.

The building MPC is in charge of controlling the heating, ventilation and air-conditioning (HVAC) plants considering both economic and comfort goals. The building under control is an existing five-floor commercial center, previously studied, modeled and controlled with classic regulation techniques [2]. The main actuators are fan-coil units, which have their inlet and outlet pipes connected with a central heating plant, using water as thermal vector. Supply water temperature and fancoils on-off signals are used in the MPC to control the temperature of each floor separately. The second MPC is instead used for managing the battery SOC and it pursues the general goal of minimizing power flow at PCC. This corresponds to tracking a zero set point for the PCC power flow. The interaction between the two MPCs is given by the exchange of the manipulated variable prediction over the control horizon. In particular, at every step, the battery MPC reads the scheduled building power consumption over its control horizon and uses this information to control the power flow at the PCC. In addition, both building and battery MPC receive in input a prediction of the RES power production, which accounts as zero-cost power over the prediction and control horizon. Further considerations can be made:

- $\quad$ both controllers parameters are tuned considering constraints in the optimization problem;

- an important role is played by RES production estimators, since it is given in input to both controllers in order to perform an optimal power schedule over the control horizon.

The distributed approach here described allows a very easy scalability: the presence of more buildings, each equipped with its MPC controller, is managed by simply summing up each one's predicted power consumption and deliver this information to the battery at PCC, which is operated exactly in the same way, simply serving a set of buildings instead of a single one.

\section{MPC FOR THE BUILDING}

The goal of building MPC is to optimize the temperature control. The building mathematical model is discussed in [2] and it is complex and non-linear. Instead, the model used for tuning the MPC controller is the linearized around an appropriate operating point, which was chosen to be $50^{\circ} \mathrm{C}$ for fan coils supply water temperature and $20^{\circ} \mathrm{C}$ for fan coils inlet air temperature. In the presented work, the heating season is considered. Thus, we are using a linear MPC to control a nonlinear plant around its operating point. The MPC controller can manipulate (1) the supply water temperature in the heating system (the flow was chosen to be fixed) and (2) the on/off signal of fan-coil actuators in order to achieve a desired temperature at each floor. The optimal regulator takes into account constraints on variables related to real building operation, building use (opening/closing times, limits on indoor temperatures, etc...), dynamic energy price, and prediction of power production from renewables in the micro grid. By balancing the weights in the controller objective function it is possible to account more for the user comfort or for energy auto-consumption. In addition, several disturbances, mostly related to environmental conditions, like external temperature, ground temperature, internal heat gains (due to appliances, lights, people, etc...) and solar radiation are considered. The linearized discrete building model is put in state-space form:

$$
\left\{\begin{array}{l}
\mathrm{x}_{\mathrm{k}+1}=\phi \mathrm{x}_{\mathrm{k}}+\Gamma \mathrm{u}_{\mathrm{k}}+\Gamma^{d} d_{\mathrm{k}} \\
\mathrm{y}_{\mathrm{k}}=C \mathrm{x}_{\mathrm{k}}
\end{array}\right.
$$

where:

- $\phi, \Gamma, \Gamma^{d}, C$ are appropriate matrices computed from the non-linear model described in [2];

- $\mathrm{x}_{\mathrm{k}}$ state variables, walls temperatures and room temperatures;

- $\mathrm{u}_{\mathrm{k}}$ manipulated variables, temperature of supply water in the heating system;

- $\mathrm{d}_{\mathrm{k}}$ thermal disturbances, as external temperature or solar radiation;

- $\quad \mathrm{y}_{\mathrm{k}}$ : measurable outputs: rooms temperature; 
Since many disturbances are not known or can be predicted with uncertainty and are not known in the future, a Kalman filter is introduced in order to compensate for them and even for the errors related to model mismatch between the linear and non-linear case. In particular, the idea is to augment the state of the system with disturbances representing uncertainty on the prediction of external inputs, such as outside air temperature, solar radiation and internal gains, obtaining a new $\hat{\mathrm{x}}_{\mathrm{k}}^{a}$. The model obtained is used to tune the gain $L_{k}$ of the following Kalman filter:

$$
\left\{\begin{array}{l}
\hat{\mathrm{x}}_{\mathrm{k} \mid \mathrm{k}-1}^{a}=\phi \hat{\mathrm{x}}_{\mathrm{k}-1 \mid \mathrm{k}-1}^{a}+\Gamma \mathrm{u}_{\mathrm{k}-1}+\Gamma^{d} d_{\mathrm{k}-1} \\
\hat{\mathrm{x}}_{\mathrm{k} \mid \mathrm{k}}^{a}=\hat{\mathrm{x}}_{\mathrm{k} \mid \mathrm{k}-1}^{a}+L_{k}\left(y_{k}-C \hat{\mathrm{x}}_{\mathrm{k} \mid \mathrm{k}-1}^{a}\right)
\end{array}\right.
$$

The economic MPC minimizes the following cost function, which allows for temperature tracking with cost optimization and maximization of self-consumption of RES energy:

$$
\begin{aligned}
& \min _{\Delta u} J(k)=\underbrace{\sum_{i=0}^{p}\left\|\left(r_{k+i \mid k}-\hat{\mathrm{y}}_{\mathrm{k}+\mathrm{i} \mid \mathrm{k}}\right)\right\|_{\mathrm{w}^{\mathrm{y}}}^{2}}_{(1)}+\underbrace{\sum_{i=0}^{m-1}\left\|\Delta \mathrm{u}_{k+\mathrm{i}}\right\|_{\mathrm{w}^{u}}^{2}}_{(2)}+\underbrace{\sum_{i=0}^{m-1} \mathrm{c}_{\mathrm{k}+\mathrm{i}} \mathrm{P}_{\mathrm{b}, \mathrm{k}+\mathrm{i}} \mathrm{w}^{\alpha}}_{(3)} \\
& +\underbrace{\sum_{i=0}^{m-1} c_{\mathrm{k}+\mathrm{i}}\left(\mathrm{P}_{\mathrm{b}, \mathrm{k}+\mathrm{i}}-\mathrm{P}_{R E S, \mathrm{k}+\mathrm{i}}\right) \mathrm{w}^{\mathrm{g}}} \\
& \text { s.t. }\left\{\begin{array}{l}
\mathrm{x}_{\mathrm{k}+1}=\phi \mathrm{x}_{\mathrm{k}}+\Gamma \mathrm{u}_{\mathrm{k}}+\Gamma^{d} d_{\mathrm{k}} \\
\mathrm{y}_{\mathrm{k}}=C \mathrm{x}_{\mathrm{k}}
\end{array}\right. \\
& y_{\min } \leq y_{k} \leq y_{\max } \\
& u_{\min } \leq u_{k} \leq u_{\max }
\end{aligned}
$$

where:

- $\quad \mathrm{p}$ : prediction horizon, $\mathrm{m}$ : control horizon;

- $\quad \mathrm{w}^{\mathrm{y}}, \mathrm{w}^{\mathrm{u}}, \mathrm{w}^{\alpha}, \mathrm{w}^{\mathrm{g}}$ : weight for each term

Each term of the cost function has the following purposes:

(1) is the term for set-point tracking, where:

- $\quad \mathrm{r}_{\mathrm{k}+\mathrm{i}}$ : desired room temperature at $k+i$;

- $\hat{y}_{\mathrm{k}+\mathrm{i} \mid \mathrm{k}}$ : prediction of room temperature at $k+i$.

(2) is the term for input variable regularization, where:

- $\Delta \mathrm{u}_{k+\mathrm{i}}=\mathrm{u}_{k+\mathrm{i}}-\mathrm{u}_{k+\mathrm{i}-1}$.

(3) is the term for economic MPC which accounts for price based control. When the price is high, we achieve energy consumption reduction by reducing the thermal comfort (always inside hard temperature bounds). In other words, when energy price is low, MPC overheats in order to exploit thermal inertia when energy price is high, always respecting user defined temperature constraints. The explanation of each term in the cost function is the following:

- $\quad \mathrm{c}_{\mathrm{k}+\mathrm{i}}$ : dynamic price at step $k+i$;

- $\quad \mathrm{P}_{\mathrm{b}, \mathrm{k}+\mathrm{i}}$ : building predicted power at $k+i$.

(4) is the term for tracking of renewables power, when available. Notice that the term is weighted using energy cost since the controller should privilege self- consumption when energy price is high. Thus, the more $\mathrm{c}_{\mathrm{k}+\mathrm{i}}$ increases, the more the building will deliver power closer to the renewables one. Follows the nomenclature for term (4) as well:

- $\mathrm{P}_{R E S, \mathrm{k}+\mathrm{i}}$ : predictive renewable power at step $k+i$.

\section{MPC FOR THE BATTERY}

One of the advantages brought by the presented architecture is the independent design of the controllers, such that the battery controller can have a different objective than the building controller. In the case study presented here, the feed-in tariff is such that the energy selling price is significantly lower than the energy buying price. Therefore, the battery control objective is to maximize the auto consumption by storing the energy produced locally that is not used by the building and releasing it when needed instead of buying it from the grid to serve the building load.

Given that the energy storage is controlled by power set points (constant power mode), the battery and the power converter are modeled together with a power integrator of a given roundtrip efficiency of $90 \%$. By setting the MPC constraints for the battery state of charge (SOC) in order to maintain it between $20 \%$ and $90 \%$, it is assumed that the storage unit can be controlled at constant power. For more detailed battery model and details of charging and discharging characteristics, we refer to [1]. The battery model is given in the form of generic state-space:

$$
\begin{aligned}
& d x=A_{s} x d t+B_{s} u d t \\
& S O C=C_{s} x
\end{aligned}
$$

where $\mathrm{u}$ is the power flow at the inverter in $\mathrm{kW}, \mathrm{x}$ is the battery state of charge in $\mathrm{kWh}$ and SOC is the state of charge normalized between 0 and 1 and it is related to the battery rated capacity. The battery controller is formalized as it follows:

$$
\begin{aligned}
& \min J=\sum_{k=1}^{N}\left\|P_{R E S, k}-P_{b, k}+P_{b a t t, k}+R_{P C C}\right\|_{q^{S P}}^{2}+\left\|\Delta u_{k}\right\|_{q^{U}}^{2}+\left\|p_{i} \cdot \mathrm{P}_{P C C}\right\|_{q^{P}}^{2} \\
& \text { s.t. } \quad x_{\mathrm{k}+1}=A_{S} x_{k}+B_{S} P_{\text {batt }, k} \\
& S O C=C_{S} x_{k} \\
& P_{\text {min }} \leq P_{\text {batt }, k} \leq P_{\text {max }} \\
& S O C_{\text {min }} \leq S O C_{\text {batt }, k} \leq S O C_{\text {max }}
\end{aligned}
$$

where $P_{R E S, k}$ is the power produced by local renewable energy resources, $\mathrm{P}_{\mathrm{batt}, \mathrm{k}}$ is the battery control action (power flow), $\mathrm{P}_{\text {build,k}}$ is the controlled building consumption, $\mathrm{R}_{\mathrm{PCC}, \mathrm{k}}$ is the power reference value at PCC, that is set to 0 . The problem in above equation is reformulated as a least squares problem, which is solved via quadratic programming:

$$
\min _{P_{\text {batt }}} J(k)=\frac{1}{2}\left\|P_{\text {batt }}-R\right\|_{Q}^{2}=\frac{1}{2} P_{\text {batt }}^{T} Q P_{\text {batt }}-(Q R)^{T} P_{\text {batt }}+\frac{1}{2} R^{T} Q R
$$

where:

$$
R=P_{R E S, k}-P_{\text {build }, k}+R_{P C C, k}, Q=q \cdot I_{N \times N}
$$

and $\mathrm{q}$ is a design weight factor. The problem constraints are formulated as: 
where:

$$
A P_{\text {batt }} \leq b
$$

$$
A=\left[\begin{array}{c}
I_{N \times N} \\
-I_{N \times N} \\
\Gamma \\
-\Gamma
\end{array}\right], \Gamma=\left[\begin{array}{cccc}
H_{1} & & \\
H_{2} & H_{1} & \\
\cdots & \cdots & \cdots & \\
H_{N} & H_{N-1} & \cdots & H_{1}
\end{array}\right], b=\left[\begin{array}{c}
P_{\max } \\
-P_{\min } \\
S O C_{\max } \\
-S O C_{\min }
\end{array}\right]
$$$$
H_{i}=C_{s} A_{s}^{i-1} B_{s}, \quad 1 \leq i \leq N
$$

\section{SIMULATION RESULTS}

In this section the main simulation results are presented. As stated in the previous sections, in this version of the paper we show results for the test case outlined in Sect. II, namely a scenario where battery and building are managed by different stakeholders. Battery MPC has as main objective to minimize power flow at PCC, while building MPC minimizes HVAC plants operating costs. In this article, two simulation runs are outlined. In the first one, a perfect prediction of RES is fed into battery MPC. The scope is to verify that of the overall architecture performs as expected in ideal conditions. In the second one, a prediction error is introduced in the form of random noise. Thus, real wind production and predicted one are different. In this view, the MPC is fed with real wind production measurement (updated at each time stamp) such as at every step $\mathrm{k}$ the controller can account for wrong RES production forecast. In other words, RES power measurement replaces its prediction at every time $\mathrm{k}$ :

$$
\mathrm{P}_{R E S, \mathrm{MPC}}=\left[\begin{array}{lll}
\mathrm{P}_{R E S, M E A S, \mathrm{k}} \mathrm{P}_{R E S, P R E D, \mathrm{k}+1} & \cdots \mathrm{P}_{R E S, P R E D, \mathrm{k}+\mathrm{m}-1}
\end{array}\right]
$$

This way adds RES production feedback to battery MPC, in a very simple way which improves its robustness. The aim of this second test is to evaluate the importance of predictors in the control system. In both simulation runs, the following choices and hypotheses are made:
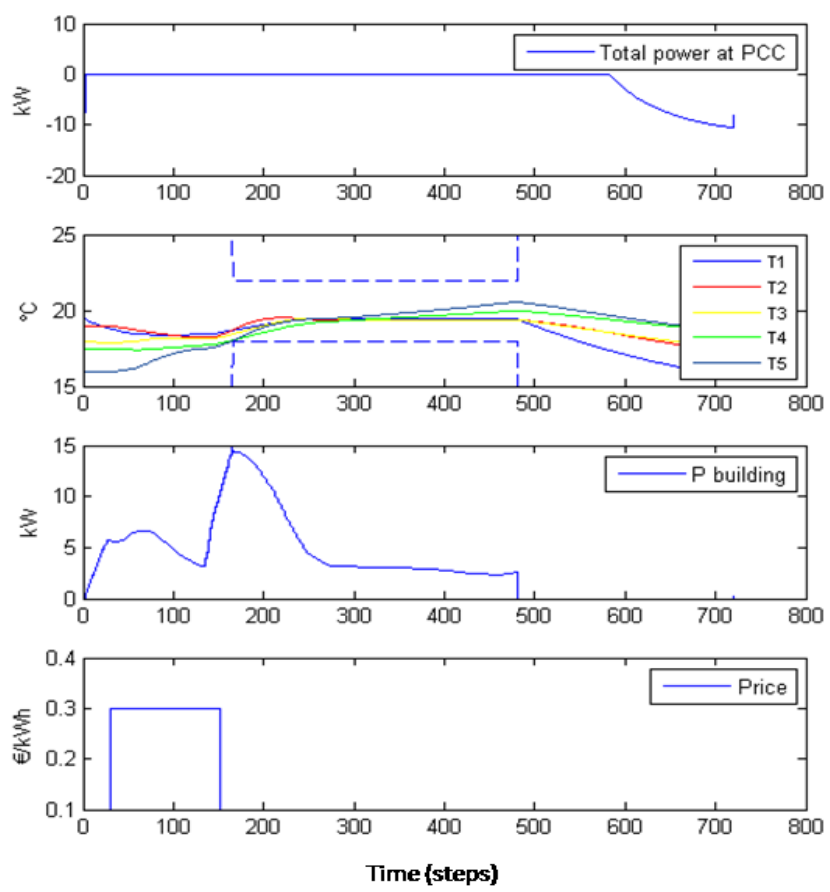

- $\quad \mathrm{c}_{\mathrm{high}}=0.30 E U R / \mathrm{kWh}$, high price value; $\mathrm{c}_{\text {low }}=0.10 E U R / k W h$, low price value;

- $\mathrm{SOC}_{\min }=20 \%$, min. battery state-of-charge; $\mathrm{SOC}_{\max }=90 \%$, max. battery state-of-charge;

- $\quad \mathrm{w}^{\mathrm{y}}=10, \mathrm{w}^{\mathrm{u}}=0.1$, thus we privilege set-point tracking w.r.t. input regularization; $\mathrm{w}^{\alpha}=$ $10, \mathrm{w}^{g}=0.1$, namely we privilege cost optimization w.r.t. renewables tracking;

- $\quad$ Sampling time $\mathrm{T}_{s}=120 \mathrm{~s}$, battery $\mathrm{MPC}$ prediction and control horizon $\mathrm{N}=30$, building MPC prediction horizon $\mathrm{P}=30$ and building MPC control horizon $\mathrm{M}=15$ simulation steps;

- $\mathrm{Q} / \mathrm{R}$ ratio for Kalman filter equal to 100 ;

- Hard constraints: $u_{\min }=20^{\circ} \mathrm{C}, u_{\max }=60^{\circ} \mathrm{C}$, $y_{\min }=19^{\circ} \mathrm{C}$ and $y_{\max }=23^{\circ} \mathrm{C}$. Constraints are active from 5.30am to $4 \mathrm{pm}$.

Main simulation results are shown in Figure 2 and Figure 3. Starting from results in Figure 2, it is possible to draw some conclusions concerning designed system capabilities. Concerning building MPC, it successfully controls internal temperature respecting upper and lower limits (dashed lines, which vary between day and night). This controller performs the best possible cost optimization since consumption is reduced when price is high and automatically shifted before and after the high price time slots: notice that this is done not to compromise hard temperature constraints (in particular the lower one in this case). Battery MPC performs as expected as well: power flow at PCC is successfully kept around zero value until the battery reaches its upper SOC value (90\%). Then, since (1) the building does not consume energy during the night and (2) the battery is fully charged and (3) the wind turbine is still producing, then power at PCC goes negative (i.e.
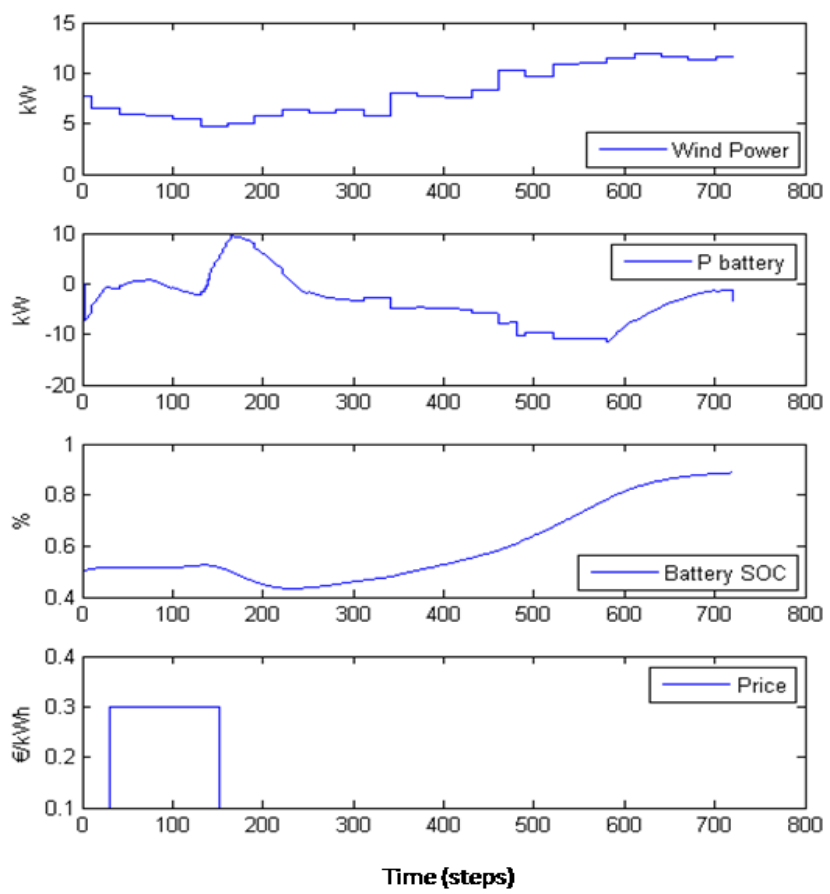

Figure 2 - Simulation results for the scenario, with perfect prediction (time in steps, each step $T_{s}=120 \mathrm{~s}$ ) 

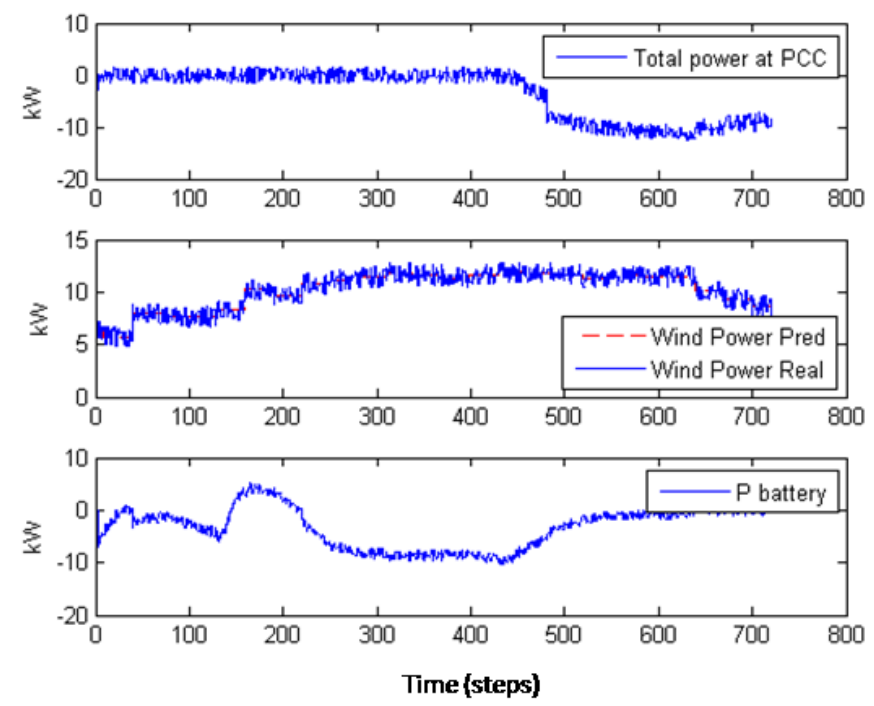

Figure 3 - Simulation results for the scenario, with prediction error and RES feedback battery MPC (time in steps, each step $T_{s}=120 \mathrm{~s}$ )

energy is sold to the grid).

Figure 3 presents the results obtained when the RES power cannot be accurately predicted. Thanks to the feedback, power at PCC remains around zero and errors introduced by wrong predictions are limited through battery compensation. Nevertheless, feedback can act every time step, thus between two consecutive steps prediction and production mismatch generate a PCC power flow different from the reference. Obviously, the bigger is the prediction error, the more the schedule goes far from the optimal one. Given this facts, we can affirm that the introduced feedback allows preserving the MPC set-point tracking capabilities, but does not guarantee the same performances from the optimality point of view. Thus the importance of having good predictors is crucial and it represents a future research goal.

\section{CONCLUDING REMARKS}

An innovative solution based on distributed model predictive controllers is introduced in this paper. The proposed solution is based on many optimal robust controllers that are associated to the main energy resources and interact exchanging basic information. The scenario addresses a smart micro grid with (1) an optimally controlled building, endowed with renewables, and (2) storage system which manages the battery in order to minimize costs and to reduce as much as possible the power flow at PCC. Similarly a smart building scenario which operates both HVAC plant and the battery, characterized by the same integration problems, can be easily modelled with the proposed approach. The integration of distributed energy resources is here implemented with MPC techniques. They guarantee robustness against model uncertainties, integration with disturbance prediction, easiness of modelling user needs and desires. Simulation results are extremely encouraging, and confirm that the choice of MPC as a reliable real-time control structure is effective.

Future works include the development of more detailed control schemes to facilitate the modeling of different scenarios, deep study and evaluation of RES power production predictors (especially for wind and PV sources), with the aim of providing and extensive testing within a real and consistent experimental setup.

\section{REFERENCES}

[1] F. Marra, G. Y. Yang, C. Traholt, E. Larsen, C. Rasmussen, and S. You, "Demand profile study of battery electric vehicle under different charging options," in Power and Energy Society General Meeting, 2012 IEEE, 2012, pp. 1-7.

[2] G. Mantovani and L. Ferrarini, "Modeling and control of thermal energy of a large commercial building," IEEE International Workshop on Intelligent Energy Systems (IWIES), Wien, 14 Nov. 2013, pp.1-6.

[3] U.S. Department of Energy, Energy efficiency and renewable energy, Energy data-book http://buildingsdatabook.eren.doe.gov/.

[4] Jan Maciejowski, Predictive Control with Constraints, Prentice Hall, 2002 (ISBN 020139823 0).

[5] Yi Zong; Kullmann, D.; Thavlov, A.; Gehrke, O.; Bindner, H.W., "Active load management in an intelligent building using model predictive control strategy,"PowerTech, 2011 IEEE Trondheim, vol., no., pp.1,6, 19-23 June 2011.

[6] Halvgaard, R.; Poulsen, N.K.; Madsen, H.; Jorgensen, J.B., "Economic Model Predictive Control for building climate control in a Smart Grid," Innovative Smart Grid Technologies (ISGT), 2012 IEEE PES, vol., no., pp.1,6, 16-20 Jan. 2012.

[7] Yudong Ma; Borrelli, F.; Hencey, B.; Coffey, B.; Bengea, S.; Haves, P., "Model Predictive Control for the Operation of Building Cooling Systems," Control Systems Technology, IEEE Transactions on, vol.20, no.3, pp.796,803, May 2012.

[8] Oldewurtel, F.; Parisio, A.; Jones, C.N.; Morari, M.; Gyalistras, D.; Gwerder, M.; Stauch, V.; Lehmann, B.; Wirth, K., "Energy efficient building climate control using Stochastic Model Predictive Control and weather predictions," American Control Conference (ACC), 2010 , vol., no., pp.5100,5105, June 30 2010-July 22010.

[9] Braun, James E., and Kyoung-Ho Lee. "An Experimental Evaluation of Demand Limiting Using Building Thermal Mass in a Small Commercial Building." ASHRAE transactions 112.1 (2006).

[10] Lamoudi, Mohamed Yacine, Mazen Alamir, and Patrick Béguery. "Unified NMPC for multi-variable control in smart buildings." IFAC 18th World Congress, Milano, Itlay. 2011.

[11] Maasoumy, Mehdi. "Model predictive control approach to online computation of demand-side flexibility of commercial buildings HVAC systems for supply following." IEEE American Control Conference (ACC 2014). 2014. 